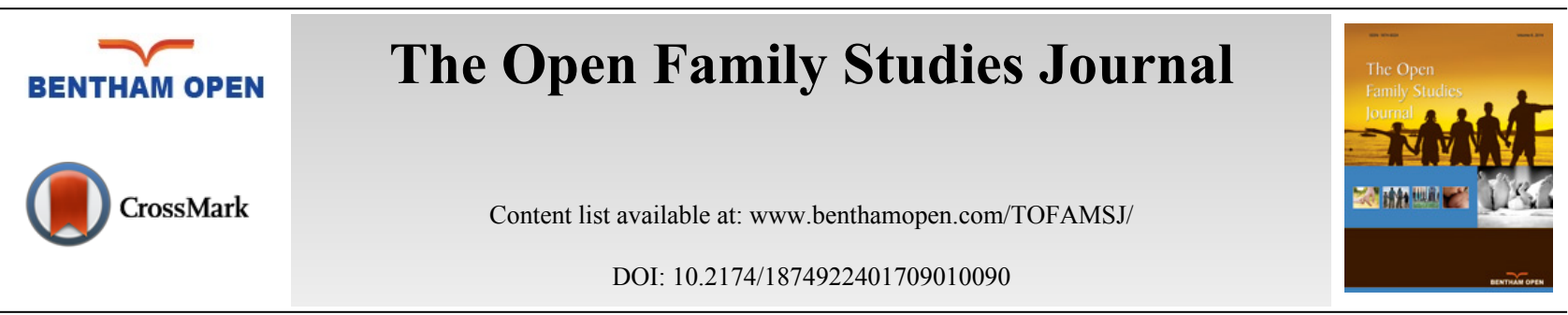

RESEARCH ARTICLE

\title{
Possibilities for Home and School Partnering Interactions Among Children with Emotional and Behavioral Disorders and Attachment Issues
}

\author{
Candace Schlein ${ }^{*}$ and Raol J. Taft \\ University of Missouri - Kansas City, Kansas, Missouri, USA
}

Received: June 30, 2017

Revised: August 14, 2017

Accepted: September 12, 2017

\begin{abstract}
:
Background:

Students with Emotional Behavioral Disorder (EBD) and those with attachment issues, such as Reactive Attachment Disorder (RAD), present school professionals with some of the most challenging behaviors experienced in schools. Family participation can be critical for promoting positive outcomes for children with behavioral concerns. Positive school and family partnering interactions can positively impact students behaviorally, academically, and socially.
\end{abstract}

\section{Objective:}

This article aims to provide an introductory framing for this special issue regarding school and family partnering interactions among students with EBD, including those with attachment issues, such as RAD.

\section{Method:}

Qualitative research was employed to consider this topic across included special issue articles.

\section{Conclusion:}

A variety of studies showcase ways of effectively attending to the experiences of students with EBD and RAD and their families. There is further much that might be gained by making use of an interdisciplinary lens for approaching this issue, such as from the perspective of education, psychotherapy, educational psychology, and family studies. This multi-perspectival approach might contribute to the life quality and success of youth with EBD and RAD and their families.

Keywords: Emotional and Behavioral Disorders, Reactive Attachment Disorder, Diversity, Family, Curriculum stakeholders, Homeschool partnerships, Special education.

\section{INTRODUCTION}

Children with Emotional and Behavioral Disorders (EBD) need to be a part of a support system that provides strong bridges between home and school, which can provide a system of support across multiple domains [1,2]. For student with Reactive Attachment Disorder (RAD) it may be even more crucial for schools and families to work together effectively [3, 4]. For this reason, it is crucial that schools connect with families regarding the needs of their children. Moreover, it is important for families' voices to be heard in schools so that schooling environments, and teacherdirected learning activities and learning expectations, can be shaped in accordance with the needs, desires, and expectations of children and their families [5]. Children with RAD are a student population that particularly needs the establishment of communication and alliance across the school and family due to manipulative actions and/or potential

* Address correspondence to this author at the University of Missouri-Kansas City, 324 Education Bldg ., 615 E.52 $2^{\text {nd }}$ St., Kansas City, MO. 64110, USA; Tel: 816-235-5754; E-mail: schleinc@umkc.edu 
behaviors that might be hidden, context-dependent, or person-dependent [6].

While there is considerable literature generally on children with EBD, there is a paucity of research on children with RAD [7]. Although children with RAD display some of the most challenging behaviors to address in our schools [8, 9], the disorder remains difficult to diagnose and treat. Teachers, teacher educators, special education para-educators, student teachers, social workers, psychologists, and guidance counsellors may all benefit from research focusing on family and school relationships pertaining to this student population.

Moreover, very little qualitative investigations exist on this subject area. Qualitative research on children with EBD, attachment issues, and/or RAD and their families may serve to voice their experiences and improve their lives inside and outside of school. Qualitative research produces valid science-based evidence, including information about "physical, material, and social worlds" [10] that can effect special education policy and practice [11]. The purpose of qualitative research as it relates to special education answers questions of what, why, and how something is occurring. Qualitative research leads to an understanding of not only individuals with disabilities, but also their families and others who work with or provide services for families of and individuals with disabilities. Qualitative studies can be used to investigate impact of practices, contexts, settings, and strategies used in the education of individuals with disabilities. Further, they can explore the effect these variables have on individuals and their families.

Stories of individuals are often used to exemplify the experiences of individuals with disabilities. An early example of a qualitative case study would be Anne Sullivan Macy's work with Helen Keller [12]. Qualitative research is anchored in real life contexts and reflects real situations and problems. As such, qualitative research serves to connect situations with ethical, moral, or political dilemmas that otherwise would remain unknown to those who might be able to address particular issues and assist in resolving them [10]. Stories of individuals with disabilities may serve to facilitate other educators' and non-educators' understanding of the needs and struggles that individuals with disabilities undergo daily in the course of their lives [10,11]. These disciplined stories, according to Pugach [4], facilitate achievement of the rights afforded individuals with disabilities today.

Gauging by the dissemination of research, special education has been slow to accept qualitative research as a form of empirical investigation [10]. Qualitative research in special education can be a powerful tool that can be used to address what may be socially constructed injustices. If disability is socially constructed, "then knowledge of disability exists within these social constructions" [10]. That is what makes qualitative research such a positive and effective tool for investigating disability.

Qualitative research in special education might further serve a role in providing persons with disabilities with voice and empowerment [12]. These stories might offer an avenue for advocacy that is different than that presented by quantitative methods. Qualitative research also might offer a way to connect the reader with the experiences of families of and individuals with disabilities on a more intimate level that other methods of research cannot achieve, while allowing the voices of those with disabilities to be heard [10]. It is important that qualitative researchers continue to provide an avenue for the voices of those with disabilities and that they provide valuable evidence that can be used to inform practice and policy [11].

Moreover, qualitative research produces valid science-based evidence including information about "physical, material, and social worlds" [11] that can affect special education policy and practice [11]. The purpose of qualitative research as it relates to special education answers questions of what, why, and how is something occurring. This form of investigation might lead to understanding of individuals with disabilities, their families, and others who work with or provide services for families of and individuals with disabilities. Qualitative studies can also be used to investigate impact of practices, contexts, settings, and strategies used in the education of individuals with disabilities. Further, they can explore the impact these variables have on individuals and their families.

\section{SPECIAL ISSUE OVERVIEW}

This guest-edited special issue of The Open Family Studies Journal, entitled "Qualitative explorations of familyschool relationships regarding children with EBD and RAD," examines multiple qualitative facets of connections between families and schools related to students with EBD and/or RAD or other attachment issues. This journal special issue includes a set of 7 journal articles on this topic from different academic fields, which coalesce with a focus on family and school interactions and a qualitative research perspective and/or consideration of ways in which the qualitative methodology might further support the literature in this area. The studies and manuscripts in this themed issue include research articles and conceptual argument articles that express the work of behavior and family specialists 
and academics in the areas of education and psychology. A brief summary of each article is included below to provide a snapshot of the special issue.

In "The introduction of emotion coaching as a whole school approach in a primary specialist social emotional and mental health setting: Positive outcomes for all," Gus, Rose, Gilbert, and Kilby highlighted the potential of adopting a whole school approach to attachment awareness in meeting the needs of students with attachment issues. They discussed the findings of a case study into the use of emotion coaching across a special school as a means of shaping an attachment aware school that aids students in developing their emotional awareness. Significantly, the authors displayed a positive impact of the use of emotion coaching on student self-regulation. In addition, emotion coaching was seen as also building positive interactions between the school and family. This important study thus offers one means for effectively impacting students, parents, teachers, and school staff.

Wenger, Crump, LaFollette, and Kurtz reported on a literature review of research on students with EBD and/or RAD in "Explorations of family-school relationships regarding children with RAD and/or EBD: TA review of relevant literature from 1995-present." The authors shed light on the kinds of qualitative investigations on school and family relationships that have been undertaken in the areas of EBD and RAD over the past 15 years. They further argued that qualitative work on this topic has been slow but gaining momentum over the past several years, suggesting more use of qualitative methods as investigative tools in this area.

In "Understanding parent-school communication for students with emotional and behavioral disorders," Buchanan and Clark identified communication patterns between parents and schools and considered barriers to interactions between parents and schools regarding advocacy for students with EBD. Importantly, school type and school culture were seen as impacting the quality and quantity of such home-school relationships. Moreover, recommendations were provided to aid in establishing proactive and successful communication patterns between all schools and families.

In "Effectiveness of therapeutic attachment camps for improving behavior in children with Reactive Attachment Disorder," Coleman and Coleman provided a psychotherapeutic lens to issues of attachment. In their work, they examined the findings of an inquiry into the Families by Design, Healing Heart Camps, which is highlighted as a successful intensive therapy family camp that is targeted at attachment among children with RAD. Recommendations were provided, including the need for further qualitative research that explores attachment therapy camps for whole families, and the application of these findings to the fields of social work and juvenile justice.

In "How are we doing?: Family-school relationships and children with Reactive Attachment Disorder," Taft and Schlein employed the principles of effective partnership [13] as a lens to consider the type and quality of communication between families and schools with respect to children with RAD. Effective partnership principles [13] were used to analyze the experiences of families with schools. The findings of their narrative inquiry underscored the need for increased and enhanced communication between schools and families with children with RAD. Recommendations were also provided for ways schools might attend more carefully to supporting the needs of students with RAD and their families. In particular, the authors deliberated over how to tie schools and homes more closely together, given the potential for children with RAD to triangulate their behavior and to differentiate behaviors between the home and school.

Rose, Gilbert, McGuire-Snieckus, Gus, McInnes, and Digby examined the findings of a case study into the application of the Attachment Aware Schools project as a whole school approach to improving parental engagement with schools in "Attachment Aware Schools: Working with families to enhance parental engagement and home-school relationships." The authors focused on the context of schools in England and acknowledged students with attachment issues as educationally at-risk. Significantly, the study results indicated that the Attachment Aware Schools model resulted not only in effective relationship-building between families and schools, it also led to more positive withinfamily relationships.

\section{CONCLUSION}

The overall body of work collected within this themed special issue may make a dynamic contribution to the literature. The included studies showcase ways of effectively attending to the experiences of students with EBD and RAD and their families. There is much that might be gained by utilizing an interdisciplinary lens on this topic, such as from the multiple and related viewpoints of education, psychotherapy, educational psychology, and family studies. This special themed journal issue has begun to construct such a multi-perspectival approach. Further work that ties together the perspectives from a variety of disciplines might positively contribute to the life quality and success of youth with 
EBD and RAD and their families.

We additionally anticipate that this special issue will accompany and breathe detailed life into existing quantitative studies in this area of study. We feel confident that the qualitative focus of this themed journal issue will serve to provide voice and agency to students with EBD and/or RAD or other attachment issues, as well as their families. Since there is a dearth of literature specifically on RAD, the inclusion of works targeting RAD and related attachment issues within this journal special issue may offer a significant contribution to research and practice. It is our hope that this special issue will begin to open new doors for partnering interactions between families and schools.

\section{ETHICS APPROVAL AND CONSENT TO PARTICIPATE}

Not applicable.

\section{HUMAN AND ANIMAL RIGHTS}

No Animals/Humans were used for studies that are base of this research.

\section{CONSENT FOR PUBLICATION}

Not applicable.

\section{CONFLICT OF INTEREST}

The authors declare no conflict of interest, financial or otherwise.

\section{ACKNOWLEDGEMENTS}

Declared none.

\section{REFERENCES}

[1] Farmer TW, Quinn MM, Hussey W, Holahan T. The development of disruptive behavioral disorders and correlated constraints: Implications for intervention. Behav Disord 2001; 26(2): 117-30.

[2] Yell ML, Meadows N, Drasgow E, Shriner JG. Evidence-based practices for educating students with emotional and behavioral disorders. Upper Saddle River, NJ: Pearson 2013.

[3] Cain CS. Attachment disorders: Treatment strategies for traumatized children. Lanham, MD: Jason Aronson 2006.

[4] Thomas NL. When love is not enough: A guide to parenting children with RAD-Reactive Attachment Disorder. Glenwood Springs, CO: Families By Design 2005

[5] Floyd KK, Hester P, Griffin HC, Golden J, Smith-Canter LL. Reactive Attachment Disorder: Challenges for early identification and intervention within the schools. Int J Spec Educ 2008; 23(2): 47-55.

[6] Taft RJ, Schlein C, Ramsay CM. Experiences of school and family communications and Interactions among parents of children with Reactive Attachment Disorder. IJLTER 2016; 15(1): 66-78.

[7] Taft RJ, Ramsay CT, Schlein C. Home and school experiences of caring for children with Reactive Attachment Disorder. J Ethnogr Qual Res 2015; 9(3): 237-46.

[8] Dunlap G, Fox L. Parent-professional partnerships: A valuable context for addressing challenging behaviors. Int. J. Disabil. Dev. Edu 2007; 54: pp. 273-85.

[9] Green J. Are attachment disorders best seen as social impairment syndromes? Attach Hum Dev 2003; 5(3): $259-64$. [http://dx.doi.org/10.1080/14616730310001593956] [PMID: 12944220]

[10] Pugach MC. The stories we choose to tell: Fulfilling the promise of qualitative research for special education. Except Child 2001; 67(4): 439-53.

[http://dx.doi.org/10.1177/001440290106700401]

[11] Brantlinger E, Klingner J, Richardson V, Pugach M, Richardson V. Importance of experimental as well as empirical qualitative studies in special education. Ment Retard 2005; 43(2): 92-119. 
[http://dx.doi.org/10.1352/0047-6765(2005)43<92:IOEAWA>2.0.CO;2] [PMID: 15757375]

[12] Ferguson PM, Ferguson DL, Taylor SJ. Conclusion: The future of interpretivism in disability studies.Interpreting disability: A qualitative reader. New York: Teachers College Press 1992; pp. 295-302.

[13] Turnbull AA, Turnbull HR, Erwin EJ, Soodak LC, Shogren KA. Families, professionals, and exceptionality: Positive Outcomes Through Partnerships and Trust. London, United Kingdom: Pearson 2015.

(C) 2017 Schlein and Taft.

This is an open access article distributed under the terms of the Creative Commons Attribution 4.0 International Public License (CC-BY 4.0), a copy of which is available at: https://creativecommons.org/licenses/by/4.0/legalcode. This license permits unrestricted use, distribution, and reproduction in any medium, provided the original author and source are credited. 